\title{
A Faculdade de Odontologia do Triângulo Mineiro e a implantação do Ensino Superior em Uberaba (Minas Gerais, Brasil) na década de 1950
}

\author{
The Dentistry School of the Minas Triangle Region and implementation of \\ Higher Education in Uberaba (Minas Gerais, Brazil) in the 1950's \\ La Facultad de Odontología del Triángulo Minero y la implantación de la \\ Enseñanza Superior en Uberaba (Minas Gerais, Brasil) en la década de 1950
}

NeIRIMAR de CAStilho FerreirA ${ }^{1}$; Giseli Cristina do VALE GATti²

\section{Resumo}

Trata-se da comunicação de resultados finais de investigação no campo da História da Educação, na temática específica da História das Instituições Escolares, que teve como objeto a Faculdade de Odontologia do Triângulo Mineiro, com destaque para as motivações de sua criação e para seu funcionamento inicial, o que compreendeu desde 1947, ano de sua autorização, até o ano de seu reconhecimento, em 1950. A investigação foi desenvolvida com subsídios consistentes das principais referências teóricometodológicas da pesquisa historiográfica sobre as instituições escolares, notadamente, Magalhães (1998, 1999, 2004) e Nosella; Buffa (2009), que contribuíram com as principais categorias de análise utilizadas na presente investigação, colaborando, deste modo, para o refinamento da análise histórica-educacional sobre as primeiras iniciativas relacionadas ao ensino superior na cidade de Uberaba, em Minas Gerais, Brasil, em específico, sobre a Faculdade de Odontologia do Triângulo Mineiro.

Palavras-chave: História da Educação. Ensino Superior. Instituições Escolares.

\footnotetext{
${ }^{1}$ Professora de Planejamento de Comunicação do Curso de Comunicação Social da Universidade de Uberaba. Mestre em Educação: Processos educacionais e seus fundamentos, pelo Programa de PósGraduação em Educação da Universidade de Uberaba. E-mail: neirecastilho@gmail.com

2 Doutora em Educação, com estágio de pós-doutorado concluído no Programa de Pós-Graduação em Educação da Universidade Federal de Uberlândia. Professora Permanente do Programa de Pós-Graduação em Educação da Universidade de Uberaba. Beneficiária do Edital Universal da Fapemig. Email:giseli.vale.gatti@gmail.com
} 


\section{Abstract}

This study communicates the final results of an investigation in the field of History of Education, specifically within the theme of the History of School Institutions, the object of which was the Dentistry School of the Minas Triangle region (Faculdade de Odontologia do Triângulo Mineiro), Brazil, highlighting the reasons for its establishment and its initial operation, encompassing the period from 1947, the year it was authorized, to the year of its recognition, 1950. The investigation was developed under the solid support of the main theoretical-methodological references of historiographical research in regard to school institutions, notably, Magalhães (1998, 1999, 2004) and Nosella and Buffa (2009), which contributed the main categories of analysis used in the present investigation. Consequently, this framework collaborated in refining the historical-educational analysis regarding the first initiatives related to higher education in the city of Uberaba, Minas Gerais, Brazil, and, specifically, in regard to the Dentistry School of the Minas Triangle region.

Keywords: History of Education. Higher Education. School Institutions.

\section{Resumen}

Se trata de la comunicación de resultados finales de investigación en el campo de la Historia de la Educación, en la temática especifica de la Historia de las Instituciones Escolares, que tuvo como objeto la Facultad de Odontología del Triángulo Minero, con destaque para las motivaciones de su creación y para su funcionamiento inicial, el que comprendió desde 1947, año de su autorización, hasta el año de su reconocimiento, en 1950. La investigación fue desarrollada con subsidios consistentes de las principales referencias teórico-metodológicas de la investigación historiográfica sobre las instituciones escolares, notadamente, Magalhães (1998, 1999, 2004) e Nosella; Buffa (2009), que contribuyeron con las principales categorías de análisis utilizadas en la presente investigación, colaborando, de este modo, para el refinamiento del análisis histórico-educacional sobre las primeras iniciativas relacionadas con la enseñanza superior en la ciudad de Uberaba, en Minas Gerais, Brasil, en específico, sobre la Facultad de Odontología del Triángulo Minero.

Palabras-clave: Historia de la Educación. Enseñanza Superior. Instituciones Escolares. 
Este trabalho aborda os resultados de investigação sobre o contexto histórico e sobre as circunstâncias da criação e do funcionamento inicial do Curso de Odontologia na cidade mineira de Uberaba, em Minas Gerais, no Brasil, com observação detalhada do perfil, da formação, da organização do corpo docente e dos saberes disseminados.

O período analisado compreende desde o ano de sua autorização, em 1947, até o ano de seu reconhecimento em 1950, dado o recorte temático e espaço-temporal, o universo da pesquisa compreendeu alunos, professores, dirigentes e imprensa local de então, cujos procedimentos investigativos incluíram a aproximação e o reconhecimento do tema, visitas à instituição, leitura e análise dos documentos disponíveis no Arquivo Público Municipal e no próprio acervo da Uniube. Também são relacionadas as principais referências teórico-metodológicas da pesquisa historiográfica de instituições escolares proposta por Magalhães (1998, 1999, 2004) e Nosella; Buffa (2009) para o entendimento da história da Faculdade de Odontologia do Triângulo Mineiro e a sua relação com o contexto local, regional e nacional.

A exposição está estruturada em duas partes, com a exposição, primeiramente, das tentativas de implantação do Ensino Superior na cidade de Uberaba até a criação da Faculdade de Odontologia do Triângulo Mineiro e, em seguida, da abordagem da organização didática, do perfil dos docentes e dos discentes, dos saberes veiculados e dos principais eventos ocorridos nos anos que estiveram relacionados à formação da primeira turma do Curso de Odontologia da Faculdade de Odontologia de Uberaba.

\section{Das primeiras iniciativas à criação da Faculdade de Odontologia do Triângulo Mineiro}

A ideia inicial de Mário de Ascenção Palmério $^{3}$ em relação à instituição de ensino superior na cidade de Uberaba era a criação de uma Faculdade de Ciências Econômicas e de Escolas Técnicas de Química e Eletricidade. Contudo, reconhecendo que Uberaba não era propriamente uma cidade industrial e, informado de que o município contava com algo em torno de quarenta ou cinquenta dentistas em situação regular para uma população de cerca de 70 mil habitantes, resolveu rever os planos (Relatório, 1947). Assim, no ano de 1947, o professor Mário de Ascenção Palmério convidou os cirurgiões dentistas Feliciano

\footnotetext{
${ }^{3}$ Mineiro, da cidade de Monte Carmelo, Mário Palmério nasceu no dia $1^{\circ}$ de março de 1916 , cursou o ensino secundário formal em duas instituições de orientação católica, ambas localizadas no Triângulo Mineiro. Em 1929 iniciou os estudos no Ginásio Diocesano de Uberaba e permaneceu até 1931. No ano seguinte cursou a $4^{\mathrm{a}}$ série no Ginásio Regina Pacis, em Araguari; porém, em 1933 retornou ao Diocesano para concluir os estudos do $2^{\circ}$ Ciclo. Ao concluir os estudos secundários, o pai decidiu que Mário Palmério, então com 17 anos, deveria se inscrever na Escola Militar do Realengo, no Rio de Janeiro. Mário Palmério ingressou como cadete efetivo na Escola Militar do Realengo no dia 25 de abril de 1935, aos 19 anos de idade. No entanto, sua permanência foi breve. Matriculou-se, em 1939, na subseção de Ciências Matemáticas da Faculdade de Filosofia de São Paulo. No dia 2 de maio de 1939 foi nomeado para o cargo de professor interino da $12^{\mathrm{a}}$ Cadeira do Colégio Universitário, anexo à Escola Politécnica, ligada à Universidade de São Paulo. No dia 13 de outubro de 1939 Mário Palmério se casou na cidade de Santos (SP) com a uberabense Cecília Arantes, filha de Cacildo Arantes e de Maria Pimenta Arantes. Exerceu a docência em São Paulo até dezembro de 1939, quando, aos 23 anos, abandonou a faculdade, pediu sua exoneração do colégio e, depois de cinco anos morando longe, voltou à Uberaba para fundar o Liceu Triângulo Mineiro em 1940 (Fonseca, 2010).
} 
Henriques, Edmundo Rodrigues da Cunha e Paulo Sepúlveda, para colaborarem na estruturação e organização de uma "Faculdade de Odontologia do Triângulo Mineiro". Posteriormente, a eles uniram-se o cirurgião dentista Sultan Mattar e o médico Jorge Henrique Furtado, para compor o quadro docente. Foi também convidado o prof. Ubiratan Novaes, da Faculdade de Odontologia da Universidade Federal de Minas Gerais, para estruturar a montagem do ensino odontológico uberabense (Cunha Filho, 1983, p. 70).

No dia 21 de agosto de 1947, designada por Portaria do Exmo. Senhor Diretor de Ensino Superior do Governo Federal, a técnica de educação Nair Fortes Bau-Merhy compareceu à sede da Faculdade de Odontologia do Triângulo Mineiro para proceder à "necessária verificação" do curso de Odontologia. Em seu relatório, a inspetora classificou como "muito expressiva" a demonstração feita pela entidade mantenedora a respeito da real necessidade do Curso de Odontologia para o meio.

No referido documento, a entidade mantenedora afirma que "a ideia da fundação de um estabelecimento de ensino superior em Uberaba, que, aliás, seria o primeiro, surgiu em virtude da crise do Zebu, que em 1917 chegava ao clímax" (Relatório, 1947) e ainda refletia suas consequências na economia local. Uberaba já contara com instituições de nível superior em anos anteriores - o Instituto Zootécnico (1896) e a Escola de Farmácia e Odontologia de Uberaba (1936). A Escola de Farmácia e Odontologia de Uberaba, após formar cinco turmas de dentistas (a primeira, em 1929; a última, em 1934), obteve, por um parecer do Conselho Nacional de Educação, a sua suspensão decretada em agosto de 1936 devido a irregularidades apontadas no relatório da fiscalização federal (Loureiro, 2010) e o Instituto Zootécnico, importante vetor de desenvolvimento de pesquisas de melhoria do rebanho bovino local, foi igualmente extinto em 1898 devido à falta de recursos necessários à manutenção de seu funcionamento. Não saberíamos precisar os reais motivos pelos quais a inspetora não contesta essa informação nem porque a mantenedora o faz, se por desinformação de ambos ou para promover uma maior valorização da atual iniciativa.

As argumentações contidas no Relatório de Inspeção de 1947 revelam a preocupação do professor Mário de Ascenção Palmério com a dependência econômica do município perante as atividades relativas à criação e seleção do gado zebu, e afirma que o professor de Monte Carmelo sempre manteve permanente contato com os criadores e fazendeiros da região, portanto, "pôde avaliar a profundidade dos reflexos daquela tremenda crise na vida da cidade e do Triângulo Mineiro" (Relatório, 1947). Ao relatar a proximidade do professor com o setor em questão, o documento enfatiza que Mário de Ascenção Palmério desejava, com a criação da Faculdade de Odontologia do Triângulo Mineiro, "trabalhar no sentido do surgimento de novas iniciativas destinadas a modificar o caráter unilateral até então reinantes nessa cidade" (Relatório, 1947), ou seja, a criação do gado Zebu como atividade econômica primordial.

O texto ressalta ainda que o idealizador da Faculdade de Odontologia do Triângulo Mineiro manteve-se intimamente ligado ao problema educacional no decorrer de sua vida profissional, pois nunca exercera antes outra atividade fora do magistério ${ }^{4}$,

\footnotetext{
${ }^{4}$ A primeira iniciativa do Prof. Mário de Ascenção Palmério no campo educacional foi em parceria com sua irmã Maria Lourencina, no dia 15 de fevereiro de 1940 os dois inauguraram o Curso de Madureza "Triângulo Mineiro" em um cômodo na própria casa dos pais. Ainda em parceria com a irmã, no dia 16 de março de 1940, Mário Palmério anunciou a criação do Liceu "Triângulo Mineiro", instituição que ofereceria
} 
consequentemente, empenhou-se a fundo para concretização do seu ideal realizando "acurados estudos sobre o assunto", que o levaram a definir-se pelo curso de Odontologia, conforme relato ao Jornal Lavoura e Comércio:

Procurei estudar minuciosamente o assunto, entrando em contato com homens de governo, industriais, professores, etc. Procurava, antes de tudo, resposta para a minha pergunta: "Haverá condições para a instalação dos cursos Técnicos de Química e Eletricidade em Uberaba?" O exame das dezenas de respostas que recebi fez-me concluir ser ainda cedo para se tentar, em Uberaba, a criação de um instituto de ensino que exige, além de professores altamente especializados, a existência de estabelecimentos industriais capazes de proporcionar o estágio absolutamente necessário aos alunos que o frequentassem (Lavoura e Comércio, 1947).

No que se refere a primeira instituição de ensino superior de Uberaba, ela surgiu em um momento em que o comércio tomava um impulso ainda não atingido. Com a chegada da Mogiana $^{5}$, a cidade tornou-se ponto de convergência de todo o Triângulo Mineiro, Estado de Goiás e Sul de Mato Grosso. O Instituto Zootécnico surgiu como uma opção pública de ensino, totalmente gratuita, que não cobrava nem mesmo taxas de matrícula ou de inscrição para os exames, conforme determinava o Artigo 137 de seu Regulamento (Minas Gerais, 1896).

Dada à dedicação que o curso exigia, não era recomendável que os alunos mantivessem atividades profissionais paralelas, o que acabava afastando da instituição os jovens pobres, que não podiam prescindir do trabalho. Além disso, com a exigência da apresentação de certificados de aprovação em matérias do curso secundário (nível de ensino restrito a uma parcela ínfima da população), fechava-se o cerco que garantia aos filhos das elites (e a alguns jovens oriundos da classe média) o acesso ao Instituto Zootécnico de Uberaba.

A inauguração formal do Instituto Zootécnico aconteceu no dia 14 de agosto de 1895. As aulas iniciaram-se no mesmo mês de agosto com 19 alunos. Apesar da grave crise financeira e da falta de recursos humanos e materiais enfrentadas pelo o Instituto Zootécnico, a escola sempre atraiu o interesse dos jovens da região, ansiosos por conseguir uma vaga naquela instituição, em função dos bons serviços prestados à comunidade.

ensino primário, secundário e profissionalizante. No dia 26 de dezembro de 1941, Mário Palmério apresentou à cidade o curso ginasial do Liceu Triângulo Mineiro: a mais nova casa do ensino secundário de Uberaba que em dezembro de 1942 também oferecia cursos propedêuticos e de perito-contador da Escola de Comércio do Triângulo Mineiro. Em 23 de dezembro de 1944 aconteceu a cerimônia de diplomação de treze alunos da primeira turma do Ginásio Triângulo Mineiro que, em 1945, contaria 539 estudantes em suas novas instalações (Azevedo, 2012).

${ }^{5}$ Autorizada em 1872, a Cia. de Estrada de Ferro Mogiana ligava São Paulo e Rio de Janeiro a diversas cidades como Casa Branca (1875), São Simão (1880), Ribeirão Preto (1883), Franca (1887), Jaguara (1888) e Uberaba (1889), que, pela sua privilegiada localização geográfica, logo se destacou como o Porto do Sertão, a Princesa do Sertão, o Pórtico do Brasil Central. Uberaba era utilizada como um entreposto entre São Paulo e toda a região oeste do Brasil, ou seja, um elo de distribuição de produtos adquiridos em São Paulo e o sertão e vice-versa (BILHARINHO, 1980). 
Em seus últimos tempos, o Instituto Zootécnico de Uberaba mostrava-se praticamente abandonado pelo governo estadual. Em 04 de outubro de 1898, tendo assumido um estado quase falido, o Presidente de Minas Gerais, Dr. Silviano Brandão, assinou o Decreto $\mathrm{n}^{\mathrm{o}}$ 1.191, dispensando todo o pessoal docente e administrativo dos estabelecimentos de ensino agrícola do estado, medida que, obviamente, levou à paralisação das atividades educacionais desenvolvidas nessas escolas.

Com o fechamento do Instituto Zootécnico de Uberaba, os alunos matriculados na instituição acabaram abandonados à própria sorte, um tipo de situação comum nas escolas superiores dos primeiros tempos republicanos. Sem que existissem outras instituições congêneres em Minas Gerais que pudessem recebê-los em transferência, os alunos tentaram a matrícula em outras faculdades do Estado, mesmo que em áreas totalmente diversas da Agronomia. O Instituto Zootécnico de Uberaba extinguiu-se em 1898, mas, com o auxílio dos técnicos lá formados, os coronéis locais passaram cuidar ainda mais da melhoria do rebanho bovino, por meio da introdução de matrizes zebuínas, e a agropecuária regional ganhou contornos mais científicos.

No início do século XX, especificamente em meados da década de trinta, os embates no cenário político eram frequentes. Até 1930, a autoridade máxima da cidade era o denominado Agente Executivo e o Presidente da Câmara. E foi na gestão do Agente Executivo e Presidente da Câmara Cel. Geraldino Rodrigues da Cunha (março de 1925 a maio de 1927) que se instalou, na cidade, a Escola de Farmácia e Odontologia de Uberaba (Mendonça, 1974, p. 187), segunda instituição de ensino superior de Uberaba e região.

A fundação da Faculdade de Odontologia e Farmácia de Uberaba está estreitamente ligada ao Dr. Francisco Mineiro Lacerda ${ }^{6}$, médico-cirurgião da Santa Casa de Misericórdia de Uberaba, cidade na qual passou a residir a partir de 1925, quando assumiu o cargo de major-médico do $4^{\circ}$ Batalhão da Brigada Policial, substituindo o Dr. Bernardino.

A Escola de Farmácia e Odontologia de Uberaba iniciou as atividades no dia 07 de julho de 1927 e o reconhecimento inicial da nova faculdade não tardou: em 21 de setembro de 1927 o governo estadual publicou a lei $n^{0} 1004$ que reconhecia seus cursos, porém, o reconhecimento em nível estadual era importante, mas não era o suficiente, já que a escola necessitava obter, também, o reconhecimento federal. Para isso, era necessário que o estabelecimento passasse por dois anos de fiscalização federal contínua. Em abril de 1934, o Conselho Nacional de Educação ordenou uma fiscalização especial na escola, que foi realizada pelo Dr. Jurandyr Lodi, o qual apontou uma série de irregularidades no funcionamento da escola uberabense. Após alguns meses, um novo parecer ( $\left.n^{\circ} 206\right)$ foi emitido pelo Conselho Nacional de Educação, confirmando o anterior e novamente apontando as várias irregularidades presentes na Escola de Farmácia e Odontologia. $\mathrm{O}$ parecer $n^{\circ} 206$ pedia ao ministro da Educação medidas punitivas contra a escola como cassação da regalia de inspeção preliminar outorgada à Escola de Farmácia e Odontologia

\footnotetext{
${ }^{6}$ (Francisco) Mineiro Lacerda era natural de Ouro Fino-MG. Formou-se médico no Rio de Janeiro, em 1904. Foi, por alguns anos, médico cirurgião e clínico especializado em moléstias contagiosas (sífilis, lepra e doenças venéreas), na Santa Casa da Capital federal, onde foi assistente do famoso Prof. Antônio Aleixo (Lavoura e Comércio, 14/02/1926). Residiu, depois, na cidade de Belo Horizonte, antes de transferir-se para Uberaba.
} 
de Uberaba e a revisão do registro de diplomas da escola, a fim de serem cancelados os que não estivessem de acordo com as prescrições legais (Brasil, 1935). A Escola de Farmácia e Odontologia de Uberaba ainda conseguiu formar, nos exames de primeira época, 23 odontólogos e 16 farmacêuticos. Essas teriam sido as últimas turmas formadas pela Escola de Farmácia e Odontologia de Uberaba.

Os arquivos da Escola de Farmácia e Odontologia de Uberaba foram recolhidos pela Inspetoria Geral do Ensino Superior, estabelecida no Rio de Janeiro. Os alunos que ainda cursavam as faculdades transferiram-se, em sua maioria, para as escolas congêneres de Ribeirão Preto e Outro Preto. Os materiais e equipamentos foram vendidos às faculdades de Outro Preto e Alfenas (Cunha Filho, 1983). Além disso, todos os farmacêuticos e dentistas formados em 1934, 1935 e 1936 foram obrigados a submeter-se a exames de revalidação de seus diplomas, feitos em faculdades reconhecidas pelo governo federal.

Segundo Riccioppo Filho (2007), independentemente das supostas irregularidades cometidas pela direção daquela instituição de ensino, o fechamento da Escola de Farmácia e Odontologia de Uberaba representou um duro golpe nas famílias de Uberaba e região que não pertenciam às elites econômicas. Apesar de pagas, a instituição dirigida por Mineiro Lacerda era a única opção para aqueles que não tinham condições econômicas para custear estudos superiores em outras localidades. Embora também servissem aos interesses de um grupo empresarial, aquelas escolas tiveram o mérito de incluir uma parcela da população que, de outra forma, estaria impossibilitada de obter o diploma de nível superior.

A Faculdade de Odontologia do Triângulo Mineiro, fundada em 1947, terceira instituição de ensino superior criada em Uberaba e a única dentre as três primeiras que teve continuidade, exerceria a função de graduar jovens que aspiravam à ascensão social por meio da obtenção do diploma.

Essa premissa pode ser previamente vislumbrada nas palavras preconizadas por seu principal idealizador e fundador, Mário de Ascenção Palmério, quando ele ainda cogitava a criação de uma Faculdade de Ciências Econômicas e de Escolas Técnicas nas áreas de Química e de Eletricidade. Palmério fez questão de frisar que os cursos a que se referia não deveriam ser confundidos com a instrução profissionalizante, tal como ministrada no Serviço Nacional de Aprendizagem Industrial (Senai), por exemplo: "Esses cursos são de nível inferior, formando profissionais de outro tipo: marceneiro, ferreiros, mestres dos diversos ofícios etc." (Fonseca, 2012, p.106).

As oportunidades vislumbradas para a criação do curso de Odontologia não se limitavam à cidade de Uberaba. O relatório de 1947 afirmava que a extensa zona territorial conhecida como "Brasil Central" não contava com nenhum estabelecimento de ensino odontológico; e essa zona compreendia todo estado de Goiás, a maior parte do estado do Mato Grosso, todo oeste de São Paulo e todo o Triângulo Mineiro. Além disso, para compreender a importância de um curso dessa natureza, na vida de uma cidade do porte de Uberaba, é preciso levar em conta, antes de tudo, as particularidades do contexto da saúde bucal da época protagonizadas pela figura do inesquecível "prático", que atendia precariamente e de forma itinerante a população urbana e rural da cidade (Cunha Filho, 1983, p. 46). 
Mário de Ascenção Palmério classificou sua preferência pela oferta de um curso de Odontologia como sendo "mais adequado e oportuno", deixando implícitas as razões da adoção do curso cujo estabelecimento deveria ser destinado a ministrar, e termina profetizando que a iniciativa representa a "pedra fundamental do futuro grande edifício universitário" (Relatório, 1947).

Figura 1 - Visita técnica, em agosto de 1947, para efeito de autorização da Faculdade de Odontologia do Triângulo Mineiro. Técnica de Educação Nair Fortes Bau-Merhy (ao centro), o casal Mário de Ascensão Palmério (à esquerda) e Dona Cecília Palmério (à direita) e os filhos Marcelo e Marília Palmério.

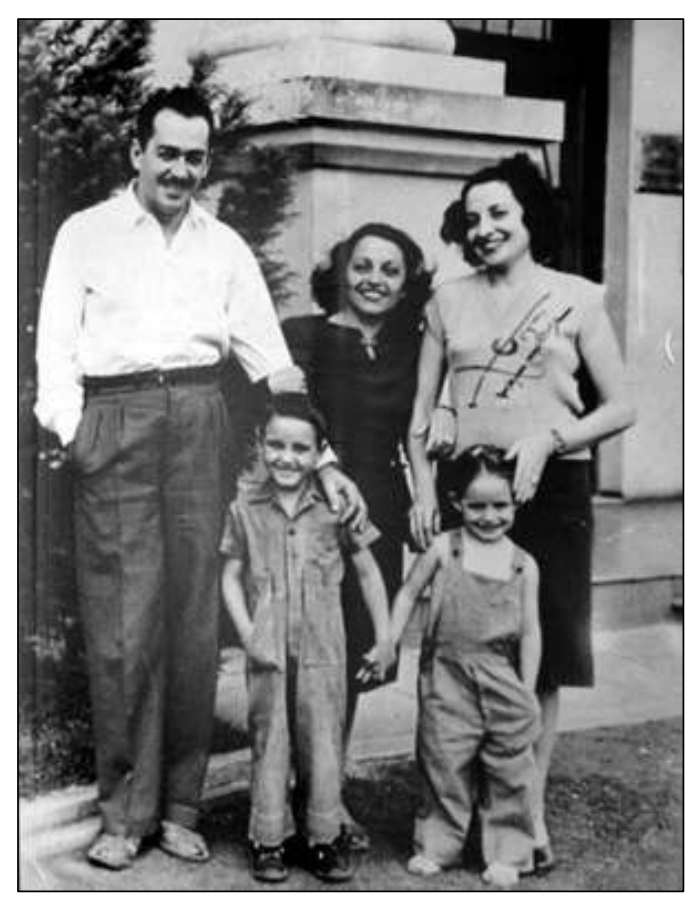

Fonte: Arquivo da Universidade de Uberaba.

A "boa vontade" em relação ao município de Uberaba é facilmente encontrada nos relatos favoráveis à instalação da Faculdade de Odontologia encontrados no relatório final de inspeção do governo. Na descrição da sua localização, por exemplo, além dos dados geográficos, a região é classificada como "zona de grandes riquezas naturais e que, por suas condições geográficas, de clima e, sobretudo, de potencial elétrico" (grandes e poderosas cachoeiras: cachoeira Dourada, cachoeira dos Patos, cachoeira do Maribondo, dos índios, da Onça, Paião, Canal de S. Simão, etc) a região fora "estudada e preferida para a localização da futura Capital Federal". O momento econômico que vivia a cidade realmente contribuiu para a instalação da Faculdade de Odontologia, porém, é preciso informar que, de fato, a escola de Mário de Ascenção Palmério já contava com a estrutura básica para sua instalação. Pelo menos era isso que constatou o "Relatório para efeito de autorização da Faculdade de Odontologia do Triângulo Mineiro". Como informamos anteriormente, a vistoria teve início no dia 21 de agosto de 1947 e levou alguns dias. Ao analisar a escrita financeira da entidade mantenedora, a inspetora verificou que o estabelecimento de ensino contabilizava um ativo 
de 4,2 milhões de cruzeiros e um passivo de 1,1 milhão (referente ao financiamento da Caixa Econômica Federal), de modo que o patrimônio líquido girava em torno de 3,1 milhões. As rendas eram provenientes das taxas de alunos no Colégio e da Escola de Comércio. A receita bruta de 1946 havia alcançado 530 mil cruzeiros; a renda líquida, por sua vez, perfizera 91 mil - ou seja, $17 \%$ da receita (já incluída no cálculo a amortização do empréstimo). A previsão orçamentária para 1947 projetava 478 mil cruzeiros de receita bruta e 81,2 mil de renda líquida.

Figura 2 - Prédio da Faculdade de Odontologia do Triângulo Mineiro, s/d.

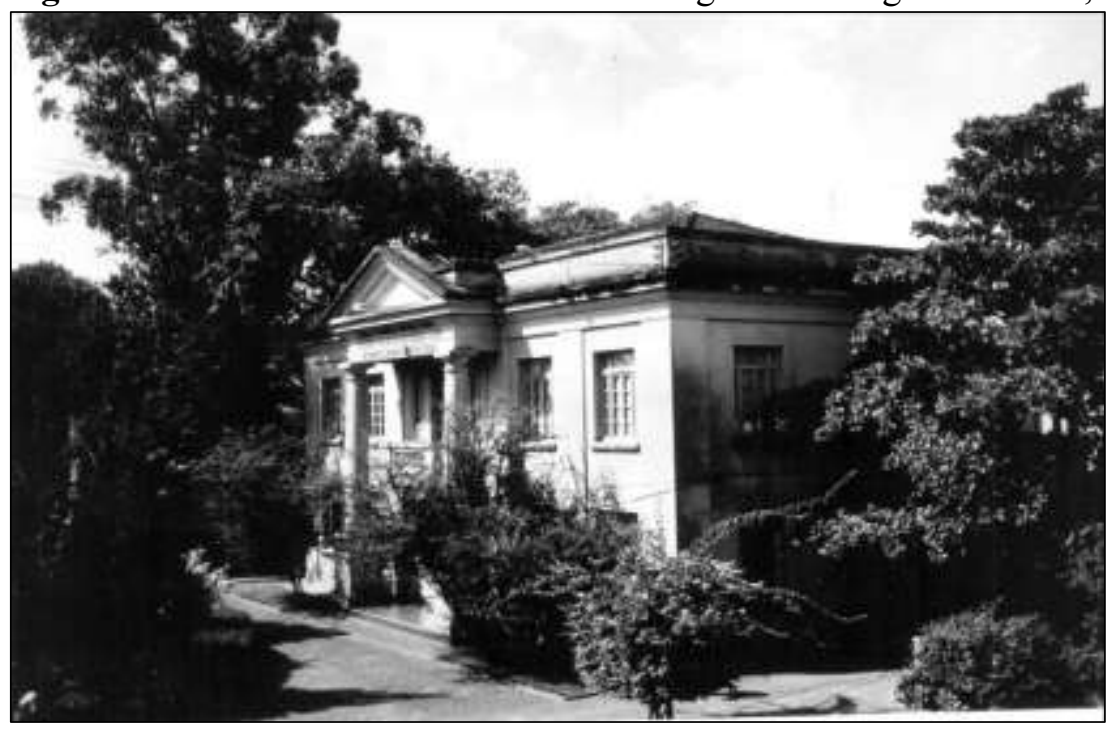

Fonte: Acervo Universidade de Uberaba, s/d.

Tendo em vista a avaliação francamente favorável, Mário de Ascenção Palmério aguardou com segurança a iminente chancela governamental. Antes disso, no dia 5 de agosto de 1947, uma manchete na capa do jornal Lavoura e Comércio noticiou, com o máximo destaque, a criação da Faculdade de Odontologia do Triângulo Mineiro, a mais nova empreitada dele. Na realidade, o curso ainda não havia sido oficialmente autorizado, pois, segundo o relatório, a decisão de oferecer o curso de Odontologia fez com que ele tivesse que adaptar o conjunto de edifícios de sua propriedade, onde já funcionavam o Colégio e a Escola Técnica de Comércio do Triângulo Mineiro, estabelecimentos também por ele criados.

Depois de mais de dois meses da inspeção, o Decreto $\mathrm{n}^{\circ} 24.132$, de 27 de novembro de 1947, autorizou o funcionamento da Faculdade de Odontologia do Triângulo Mineiro em Uberaba (Brasil, 1947). O primeiro edital anunciando os exames de habilitação à Faculdade de Odontologia do Triângulo Mineiro foi publicado no Jornal Lavoura e Comércio, em 20 de dezembro de 1947. O texto informava que seriam ofertadas sessenta vagas ao $1^{\circ}$ ano do curso e que as inscrições seriam encerradas no dia 20 de janeiro de 1948.

Entendemos que o momento econômico da cidade de Uberaba, somado à proposta de um empreendimento destacado da tradicional atividade de criação e seleção de gado zebu do município, perfizeram a matéria-prima de criação e instalação da Faculdade de 
Odontologia do Triângulo Mineiro, a iniciativa foi uma aposta do professor Mário de Ascenção Palmério, bem-sucedido em iniciativas anteriores, em parceria com a comunidade e os profissionais da área que apoiaram a iniciativa e se engajaram na consolidação da instituição. É fato que as pretensões políticas do criador da Faculdade de Odontologia de Uberaba facilitaram a aprovação e o apoio do governo àquela iniciativa. A concordância em relação à equiparação do curso à Universidade do Rio de Janeiro também foi um importante agente facilitador das negociações com a inspetoria da União. A autorização foi unânime e o consequente reconhecimento do curso em três anos, esperado como certo, de fato ocorreu: em 25 de julho de 1950, por meio do Decreto 28.416 que concedeu reconhecimento ao curso de Odontologia da Faculdade de Odontologia do Triângulo Mineiro, na cidade de Uberaba.

\section{A organização didática e a configuração docente e discente nos anos relacionados à autorização e ao reconhecimento do Curso de Odontologia da Faculdade de Odontologia de Uberaba.}

O concurso de habilitação realizado no dia 08 de março de 1948 , destinado à formação da primeira turma do curso de Odontologia da Faculdade de Odontologia do Triângulo Mineiro, contou com trinta e nove inscritos, dos quais, trinta, cursaram o segundo ciclo do ensino secundário, nomeadamente, o científico, em colégios particulares e apenas nove em colégios públicos estaduais ou municipais. Neste primeiro concurso vestibular foram oferecidas sessenta vagas e todos os inscritos foram aprovados e requereram matrícula no dia 15 de março do mesmo ano. A maioria dos candidatos, eram provenientes do Estado de São Paulo (29), seguido de Minas Gerais (5), com candidatos das cidades de Ituiutaba, Passos e Frutal, sendo que os demais candidatos vieram de outras regiões do país. Destaca-se que neste primeiro concurso não houve nenhum candidato natural da cidade de Uberaba $^{7}$.

Pode-se inferir da procedência dos candidatos (a maioria provenientes de colégios particulares) o estrato social a que pertenciam, uma vez que poucas eram as famílias com posses suficientes para manter os custos dos estudos de seus filhos em instituições particulares naquela época. Cabe aqui ressaltar que os argumentos apresentados no anexo XII do Relatório para efeito de autorização da Faculdade de Odontologia do Triângulo Mineiro acerca da manifesta utilidade de natureza cultural da cidade de Uberaba ${ }^{8}$ em receber uma instituição de ensino superior, foram colocados em xeque frente à expoente procura dos candidatos vindos de outras regiões do estado de São Paulo. O fato revelava, na verdade, uma demanda polarizada, consequência da política educacional marcadamente

\footnotetext{
${ }^{7}$ RELATÓRIO para efeito de reconhecimento do Curso de Odontologia da Faculdade de Odontologia do Triângulo Mineiro apresentado pelos membros da comissão Francisco Olybano Rosas, Eugênio Semes de Carvalho e Miguel Magalhães da Silveira em 20 de novembro de 1949, Uberaba, MG. Relatório. Datilografado. [Arquivo Universidade de Uberaba]

${ }^{8}$ O relatório de 1947 afirmava que o estabelecimento de ensino superior atenderia toda a extensa zona territorial conhecida como "Brasil Central" que compreendia todo o estado de Goiás, a maior parte do estado de Mato Grosso, todo o oeste do estado de São Paulo e todo o Triângulo Mineiro.
} 
discriminatória que promoveu, entre outras, o favorecimento das regiões mais desenvolvidas do país.

Ainda sobre este fato, destaca-se como importante ponto de análise a ausência de candidatos naturais da cidade de Uberaba no primeiro concurso de habilitação para o curso de Odontologia da instituição do Professor Mário de Ascenção Palmério. A cidade que obteve seu primeiro curso de nível superior no ano de 1896, com a criação do Instituto Zootécnico, e, mais tarde, em 1927, com a Escola de Farmácia e Odontologia de Uberaba, manteve sua desconfiança em estabelecimentos dessa natureza supostamente causada pelo fracasso de ambas as instituições de ensino.

Acerca da organização didática do curso de Odontologia da Faculdade do Triângulo Mineiro, o Regimento Interno previa as seguintes cadeiras: Anatomia; Histologia e Microbiologia; Fisiologia; Metalurgia e Química aplicadas; Técnicas Odontológicas; Cínica Odontológica ( $1^{\mathrm{a}}$ cadeira); Clínica Odontológica ( $2^{\mathrm{a}}$ cadeira); Prótese; Prótese Buco-facial; Patologia e terapêutica aplicadas; Ortodontia e Odontopediatria; Higiene e Odontologia Legal distribuídas, em três anos de curso.

Figura 3 - Histórico Escolar do Curso de Odontologia da Faculdade de Odontologia do Triângulo Mineiro

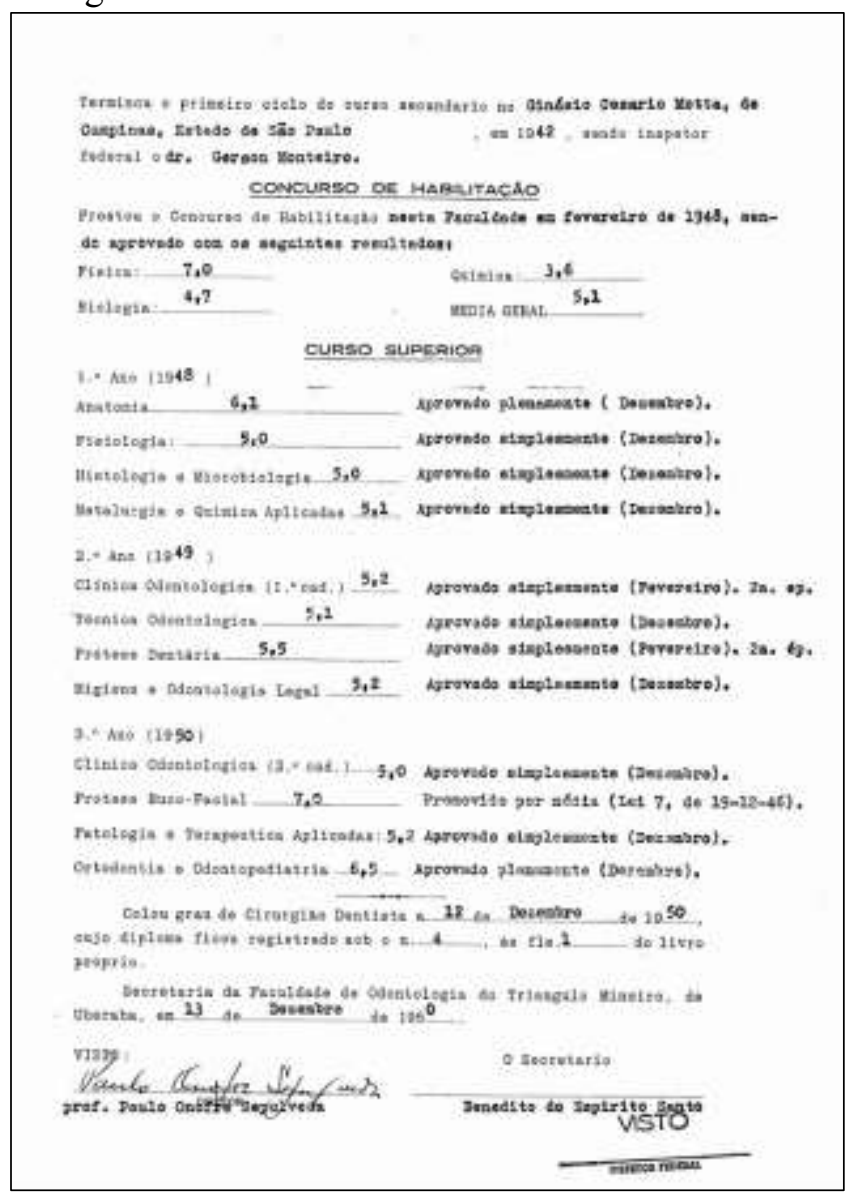

Fonte: Arquivo da Universidade de Uberaba. 
Depreende-se desta organização curricular o caráter fundamentalmente profissionalizante, criado para atender às necessidades de ordem prática das classes hegemônicas e que tinham como efeito último o bem-estar dessas elites (Riccioppo Filho, 2007, p 43). As normas de organização do corpo docente constantes no Regimento Interno da Faculdade de Odontologia do Triângulo Mineiro (Relatório, 1947) exigia dos professores catedráticos, entre outros deveres, dar, no mínimo, 12 aulas por mês, realizar aulas práticas, submeter os alunos a provas parciais e provas finais regulamentares, fornecer as notas das provas e trabalhos à secretaria dentro dos prazos fixados, apresentar relatórios quando solicitado, fazer parte das comissões examinadoras e outras as quais for designado pelo diretor, manter rigorosamente em dia o diário de classe da cadeira que estiver lecionando, destinar, semanalmente, uma hora de sua atividade para atender a consulta dos alunos, cabendo-lhe ainda, além de suas funções normais no ensino, promover e estimular pesquisas que concorram para o progresso da ciência. Tais exigências denotam a intenção manifesta de transferir para a figura do professor a total responsabilidade sobre a efetivação das funções dos estabelecimentos de ensino que, no caso da criação da Faculdade de Odontologia do Triângulo Mineiro, representaria para Uberaba "sob o ponto de vista profissional ou manifesta utilidade de natureza cultural" os seguintes resultados:

As atividades científicas de um curso de Odontologia (conferências, visitas de professores de outros institutos, concursos, cursos de especialização, intercâmbio cultural, publicações de trabalhos científicos e de pesquisa, etc., etc.) enriquecerão, sobremaneira, o cabedal de cultura dos profissionais a este ligados, contribuindo, de maneira eficiente, para a grande causa da educação, cultura e saúde do povo brasileiro (Relatório, 1947).

O parecer apresentado pela técnica de educação, Nair Fortes Bau-Merhy, em setembro de 1947, por ocasião da autorização da Faculdade de Odontologia do Triângulo Mineiro, nas suas palavras finais, revela o interesse estreito pelas instituições oriundas da iniciativa privada como política de delegação de responsabilidades aos empreendimentos particulares de ensino, na década de 40 do Século XX.

Visitei, em Uberaba, os principais clubes, associações de classe e estabelecimentos de ensino. Como é sabido, a Sociedade de Cultura Inglesa só se instala nos grandes centros culturais. E, aqui, encontrei, já florescente, essa Sociedade, que conta com cerca de 100 alunos. Os estabelecimentos de ensino secundário causaram-me verdadeira surpresa pelos edifícios e instalações, que correspondem aos dos centros mais adiantados do país. O grande número de casas de saúde e clínicas especializadas [...] fazem desta cidade uma das mais bem aparelhadas no setor da saúde pública. E o que mais impressiona é que tudo isso é fruto exclusivo da iniciativa particular (Relatório, 1947). 
Figura 4 - Primeira Turma de formandos do curso de Odontologia (1950)

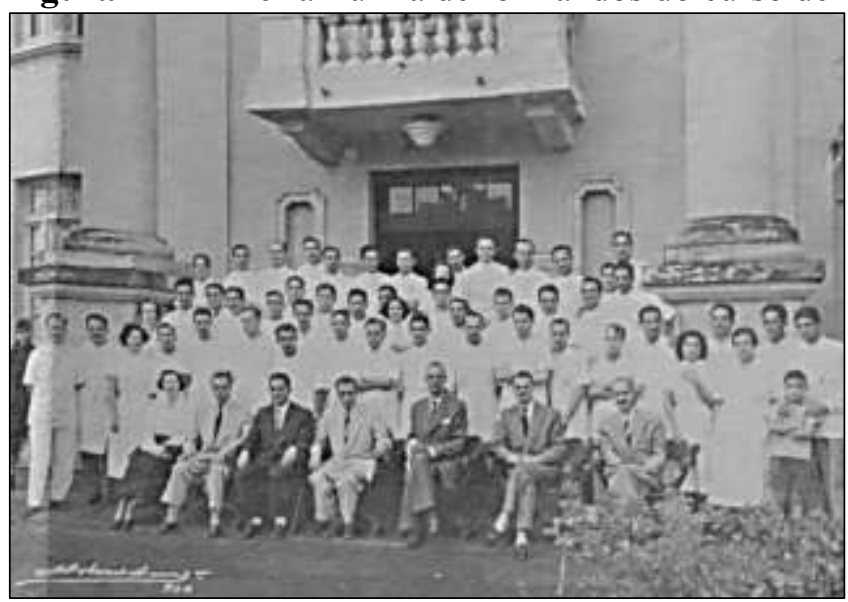

Fonte: Arquivo da Universidade de Uberaba.

O paraninfo da primeira turma de cirurgiões dentistas da Faculdade de Odontologia do Triângulo Mineiro foi o Professor Mário de Ascenção Palmério, homenagem dos graduandos ao fundador da instituição que os acolhera. Porém, as personalidades eleitas como paraninfas das demais turmas, via de regra, constituíam expoentes personalidades políticas de então, como prefeitos, deputados e até presidentes, preferência esta que denotava a íntima relação entre a referida graduação e a aspiração social dos graduandos. O paraninfo da segunda turma do curso de Odontologia (1951) foi o "Sr. Dr. Américo Renné Gianetti, digníssimo prefeito de Belo Horizonte"; o paraninfo da terceira turma (1952) foi o Sr. Dr. Adhemar Pereira de Barros, ex-governador do Estado de São Paulo. A terceira turma da recém-criada Faculdade de Direito (1951), cuja colação foi realizada juntamente com a turma de cirurgiões dentistas, foi apadrinhada por Juscelino Kubitschek.

Figura 5 - Professor Mário Palmério, Dona Cecília e Marcelo - Plantio da árvore simbólica/ formatura. $1^{a}$ Turma de Odontologia.

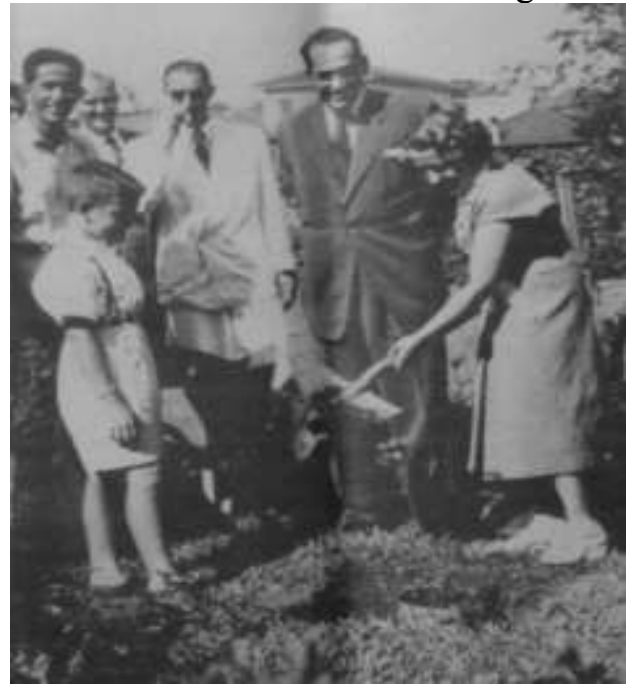

Fonte: Arquivo da Universidade de Uberaba, 1950. 
Por ocasião da formatura da primeira turma de cirurgiões dentistas, viu na colação de grau da primeira turma da Faculdade de Odontologia do Triângulo Mineiro, não apenas um momento comemorativo, mas, também, uma oportunidade para marcar simbolicamente o fato e valorizar o momento, o que foi feito por meio do plantio da árvore simbólica da primeira Turma de Odontologia, sendo que o Prof. Mário Palmério, Dona Cecília e o filho do casal, Marcelo Palmério, buscaram marcar com aquele ato, o nascimento e o crescimento daquele curso, que há três anos fincava suas primeiras raízes e, naquele momento, colhia seu primeiro fruto.

\section{Considerações Finais}

Por meio da análise dos documentos relativos à autorização e ao reconhecimento da Faculdade de Odontologia do Triângulo Mineiro, da consulta a dissertações e teses sobre o Ensino Superior na região e do estudo das narrativas da imprensa da época, conclui-se que Mário de Ascenção Palmério teve condições de neutralizar o descrédito cultivado pela população uberabense em empreendimentos educacionais de nível superior, por meio de uma notada capacidade retórica, uma habilidade para lidar com os aspectos culturais da época e com o apoio peculiar da imprensa local e regional, devolvendo, assim, a Uberaba, a confiança em empreendimentos dessa ordem.

A escolha por um curso supostamente valorizado pelas aspirações das camadas "superiores" da época foi basicamente uma escolha "sem opções", se considerarmos a natureza particular do empreendimento que necessitava das taxas pagas pelos seus alunos para manter seu funcionamento. Além disso, a declarada valorização do governo a iniciativas dessa natureza revelava a negligência e a falta de interesse público na democratização dos saberes superiores, concentrando nas elites a possibilidade de acesso ao Ensino Superior pela capacidade financeira destas de mantê-lo.

De modo geral, seria plausível assegurar que a visão empreendedora e as pretensões políticas do professor Mário de Ascenção Palmério - somadas às condições socioeconômicas de Uberaba e ao fato de que era necessário treinamento específico para quem quisesse exercer a Odontologia - representaram as principais fontes de motivação para a criação, construção e instalação de uma Faculdade de Odontologia na região.

A Faculdade de Odontologia do Triângulo Mineiro exerceu um importante papel regenerador na desconfiança arraigada dos uberabenses em relação às iniciativas desse porte no contexto local, pelas habilidades de seu fundador, que soube entender e adequar a oferta do curso às necessidades e exigências do contexto político e econômico da época.

O curso de Odontologia experimentou um ciclo de crescimento unicamente ascendente no período de 1947 a 1956, trazendo fôlego e entusiasmo para a criação de mais dois cursos: Direito (1951) e Engenharia (1956), que mais tarde viriam a ser unificados para a criação das Faculdades Integradas de Uberaba (Fiube), em 1972, que foi reconhecida como Universidade de Uberaba, pelo Ministério da Educação, em 1988, alguns anos após a fusão com as Faculdades Integradas Santo Tomás de Aquino (Fista), em 1981. 


\section{Referências}

BILHARINHO, J. S. História da medicina em Uberaba. Uberaba/MG: Editora ERG, 1980.

BRASIL. Decreto n. 24.132 de 27 de novembro de 1947 - Autoriza o funcionamento da Faculdade de Odontologia do Triângulo. Senado Federal, Brasília, DF.

BRASIL. Parecer CNE 0206/1935, de 11 de outubro de 1935, Rio de Janeiro, 1935.

CUNHA FILHO, Edmundo Rodrigues da. O passado e o presente da odontologia de Uberaba. Uberaba, Editora Vitória, 1983.

FONSECA, André Azevedo da. A consagração do mito Mário Palmério no cenário político do Triângulo Mineiro (1940-1950). Tese (doutorado) - Universidade Estadual Paulista, Faculdade de História, Direito e Serviço Social, 2010. 335 f. Disponível em: $<$ http://hdl.handle.net/11449/103080>. Acesso em 10 out. 2015.

FONSECA, André Azevedo da. A construção do mito Mário Palmério: um estudo sobre a ascensão social e política do autor de Vila dos Confins. São Paulo. Editora Unesp, 2012.

LAVOURA E COMÉRCIO, 14 fev. 1926.

LAVOURA E COMÉRCIO, 20 dez. 1947

LAVOURA E COMÉRCIO, 5 ago. 1947

LOUREIRO, Marilda Arantes. Escola de Farmácia e Odontologia de Uberaba: Gênese e desenvolvimento (1926-1936). 2010. 143 f. Trabalho de Conclusão de Curso (Dissertação) Universidade de Lisboa, Instituto de Educação da Universidade de Lisboa, Lisboa, 2010.

MAGALHÃES, Justino. Contributos para a história das instituições educativas - entre a memória e o arquivo. In: Fernandes, Rogério; Magalhães, Justino. Para uma História do Ensino Liceal em Portugal. Secção de História da Educação da Sociedade Portuguesa de ciências da Educação: Braga/Portugal. Universidade do Minho. 1999. p. 63-77.

MAGALHÃES, Justino. Tecendo Nexos: história das instituições educativas. Bragança Paulista/SP. Editora Universitária São Francisco, 2004.

MAGALHÃES, Justino. Um Apontamento metodológico sobre a História das Instituições Educativas. In SOUZA, Cynthia Pereira de; CATANI, Denice Barbara (Orgs.) Práticas Educativas, Culturas Escolares, Profissão Docente. II Congresso Luso-brasileiro de História da Educação. São Paulo: Escrituras, 1998, p. 51-69.

MINAS GERAIS. Decreto $n^{\circ}$ 975, de 27 de outubro de 1896. APROVA O REGULAMENTO DO INSTITUTO ZOOTÉCNICO.

NOSELLA, Paolo; BUFFA, Ester. (2009). Instituições Escolares: por que e como pesquisar. Campinas/SP; Alínea Editora, 2009.

RELATÓRIO para efeito de autorização da Faculdade de Odontologia do Triângulo Mineiro apresentado pelo técnico de educação Nair Fortes Bau-Merhy em setembro de 1947. Uberaba, MG. Relatório. Folha avulsa incorporada. Datilografado. [Arquivo Universidade de Uberaba].

RELATÓRIO para efeito de reconhecimento do Curso de Odontologia da Faculdade de Odontologia do Triângulo Mineiro apresentado pelos membros da comissão Francisco Olybano Rosas, Eugênio Semes de Carvalho e Miguel Magalhães da Silveira em 20 de novembro de 1949, Uberaba, MG. Relatório. Datilografado. [Arquivo Universidade de Uberaba].

RICCIOPPO FILHO, Plauto. Ensino Superior e Formação de Professores em Uberaba/MG (1881-1938): uma trajetória de avanços e retrocessos. 2007. 509 f. Trabalho de Conclusão de Curso (Dissertação) - Universidade de Uberaba, 2007. 